OPEN ACCESS

Edited by:

Cheng-Chao Ruan,

Fudan University, China

Reviewed by:

Xiaoxiang Yan,

Shanghai Jiao Tong University, China

Wai San Cheang,

University of Macau, China

*Correspondence:

Anne Dutour

Anne.DUTOUR@ap-hm.fr

Specialty section:

This article was submitted to

Cellular Endocrinology,

a section of the journal

Frontiers in Endocrinology

Received: 17 June 2021

Accepted: 27 July 2021

Published: 16 August 2021

Citation:

Lasbleiz A, Gaborit B,

Soghomonian A, Bartoli A, Ancel P, Jacquier $A$ and Dutour $A$ (2021)

COVID-19 and Obesity: Role of

Ectopic Visceral and Epicardial Adipose Tissues in Myocardial Injury.

Front. Endocrinol. 12:726967.

doi: 10.3389/fendo.2021.726967

\section{COVID-19 and Obesity: Role of Ectopic Visceral and Epicardial Adipose Tissues in Myocardial Injury}

\author{
Adèle Lasbleiz ${ }^{1,2}$, Bénédicte Gaborit ${ }^{1,2}$, Astrid Soghomonian ${ }^{1}$, Axel Bartoli ${ }^{3,4}$, \\ Patricia Ancel $^{2}$, Alexis Jacquier ${ }^{3,4}$ and Anne Dutour ${ }^{1,2 *}$ \\ ${ }^{1}$ Department of Endocrinology, Metabolic Diseases and Nutrition, Pôle ENDO, APHM, Marseille, France, ${ }^{2}$ Aix Marseille Univ, \\ INSERM, INRAE, C2VN, Marseille, France, ${ }^{3}$ Aix Marseille Univ, CNRS, CRMBM, Marseille, France, ${ }^{4}$ Department of Medical \\ Imaging, Hôpital Universitaire Timone APHM, Marseille, France
}

In March 2020, the WHO declared coronavirus disease 2019 (COVID-19), caused by severe acute respiratory syndrome coronavirus 2 (SARS-CoV-2), a global pandemic. Obesity was soon identified as a risk factor for poor prognosis, with an increased risk of intensive care admissions and mechanical ventilation, but also of adverse cardiovascular events. Obesity is associated with adipose tissue, chronic low-grade inflammation, and immune dysregulation with hypertrophy and hyperplasia of adipocytes and overexpression of pro-inflammatory cytokines. However, to implement appropriate therapeutic strategies, exact mechanisms must be clarified. The role of white visceral adipose tissue, increased in individuals with obesity, seems important, as a viral reservoir for SARS-CoV-2 via angiotensin-converting enzyme 2 (ACE2) receptors. After infection of host cells, the activation of pro-inflammatory cytokines creates a setting conducive to the "cytokine storm" and macrophage activation syndrome associated with progression to acute respiratory distress syndrome. In obesity, systemic viral spread, entry, and prolonged viral shedding in already inflamed adipose tissue may spur immune responses and subsequent amplification of a cytokine cascade, causing worse outcomes. More precisely, visceral adipose tissue, more than subcutaneous fat, could predict intensive care admission; and lower density of epicardial adipose tissue (EAT) could be associated with worse outcome. EAT, an ectopic adipose tissue that surrounds the myocardium, could fuel COVID-19-induced cardiac injury and myocarditis, and extensive pneumopathy, by strong expression of inflammatory mediators that could diffuse paracrinally through the vascular wall. The purpose of this review is to ascertain what mechanisms may be involved in unfavorable prognosis among COVID-19 patients with obesity, especially cardiovascular events, emphasizing the harmful role of excess ectopic adipose tissue, particularly EAT.

Keywords: epicardial adipose tissue, COVID-19, obesity, cardiac injury, adipose tissue, ectopic fat, inflammation, immunity 


\section{INTRODUCTION}

Since December 2019, a global pandemic of coronavirus disease 2019 (COVID-19), caused by severe acute respiratory syndrome coronavirus 2 (SARS-CoV-2), first reported in Wuhan, China, has been raging (1). Obesity, whose prevalence is rising worldwide, is currently a major public health issue. It was soon recognized as a risk factor for worse outcomes of COVID-19 (2), including the occurrence of acute respiratory distress syndrome (ARDS), but also adverse cardiovascular events in up to $28 \%$ of hospitalized patients (3). The role of ectopic fat depots, especially increased amounts of epicardial adipose tissue (EAT), has drawn interest in the COVID-19 setting because this cardiac adiposity could fuel critical illness in patients with obesity. The purpose of this review is to ascertain what mechanisms may be involved in the unfavorable prognosis of COVID-19 patients with obesity, especially cardiovascular events, emphasizing the harmful role of excess ectopic adipose tissue, particularly EAT.

\section{COVID-19 PATHOGENESIS-KEY POINTS}

The mechanisms of SARS-CoV-2 viral transmission and pathogenesis are now better understood and may explain why some patients appear to be at greater risk of severe forms. SARSCoV-2 infects the host cells by binding of the viral spike (S) proteins, present on the viral envelope, to cellular angiotensinconverting enzyme 2 (ACE2) receptors and then by employing cellular serine protease TMPRSS2 for $\mathrm{S}$ protein priming and plasma membrane fusion (4). This enables endocytosis of the virion and entry of the viral genome into the host cell cytoplasm, followed by endosomal acidification, viral replication, and shedding of virion particles (5). Type II alveolar cells, kidney cells, myocardial cells, nasal, ileum, esophagus epithelial cells, pancreatic cells, and, interestingly, adipocytes (6-8) have been identified with high ACE2 expression and could increase SARSCoV-2 infection and replication as demonstrated in a mouse model and HeLa cells $(9,10)$. Infection results in cell apoptosis, which triggers the activation of pro-inflammatory cytokines and chemokines. It has been demonstrated that SARS-CoV-2-infected patients, especially those requiring admission to intensive care units (ICUs), have large amounts of pro-inflammatory cytokines than healthy patients without SARS-CoV-2 infection (11). One of the mechanisms explaining rapid disease progression could be the "cytokine storm", a dysregulated, excessive systemic cytokine release (12). Studies have shown that serum levels of IL-6, tumor necrosis factor (TNF- $\alpha$ ), granulocyte colony-stimulating factor (G-CSF), interferon- $\gamma$-inducible protein 10 (IP-10), monocyte chemoattractant protein 1 (MCP-1), or macrophage inflammatory protein $1-\alpha$, among others, are higher in patients with severe conditions (i.e., requiring transfer to an ICU or mechanical ventilation or who died) than in other infected patients $(13,14)$. Obesity is known to be associated with a state of chronic low-grade inflammation that might be a risk factor for developing a cytokine storm form during COVID-19 disease.

\section{OBESITY: A RISK FACTOR FOR BAD COVID-19 OUTCOMES}

Obesity is increasing worldwide and is today clearly recognized as a critical risk factor for various infections, post-infection complications, and mortality from severe infection $(15,16)$. In particular, since the 2009 influenza A H1N1 outbreak, patients with obesity have been found to be at greater risk of severe disease and have needed more mechanical ventilation $(17,18)$. During the COVID-19 pandemic, poor prognostic factors have emerged such as male sex, older age, diabetes mellitus, hypertension, and the presence of prior cardiovascular or respiratory disease. These factors were associated with a greater risk of developing critical or fatal conditions $(2,19)$. Obesity was also soon recognized as an independent risk factor associated with worse outcomes $(20,21)$. The United Kingdom was the first to reveal in March 2020, through a report from the Intensive Care National Audit and Research Centre (ICNARC), that twothirds of patients who developed serious or fatal complications following infection were overweight or obese. A US study including 5,700 patients hospitalized in New York City for COVID-19 reported that the prevalence of obesity in recovered patients was twice that in the population around the hospital (41.7\% vs. 22\%) (22). A pooled meta-analysis including 19 studies showed that individuals with obesity were $113 \%$ more at risk of hospitalization $(p<0.0001)$ (23). This was confirmed by another study including 45,650 participants from nine countries worldwide and showing an odds ratio of 2.36 (95\%CI: 1.37, 4.07, $P=0.002)$ for hospitalization, and 2.63 (95\%CI: 1.32, 5.25, $P=$ $0.006)$ for invasive mechanical ventilation support (24). It has also been shown that individuals with obesity are more likely to be managed in ICUs with a need for orotracheal intubation for mechanical ventilation especially if patients are young (23, 25-27). In CORONADO, a multicentric French study of COVID-19 infection in hospitalized patients with diabetes, body mass index (BMI) was the only pre-admission criterion associated with orotracheal intubation and death at D7 especially in patients younger than 75 years $(28,29)$. In a French cohort of 5,795 patients hospitalized for COVID-19 infection, obesity doubled mortality in all age groups (30).

\section{ECTOPIC FAT AND ADIPOSE TISSUE DYSFUNCTION: KEY ELEMENTS IN THE COMPLICATIONS OF OBESITY}

Regional distribution of adipose tissue and the development of ectopic fat are major determinants of metabolic and cardiovascular diseases $(31,32)$. Dysfunction of subcutaneous adipose tissue (SAT) limits its expandability and leads to ectopic fat deposition.

\section{Adipose Tissue Dysfunction}

During weight gain, adipose tissue undergoes multiple structural and cellular remodeling processes (33) leading to a dysfunctional 
tissue. Firstly, during chronic positive energy balance, mature adipocytes expand, becoming hypertrophic to store more fat. If this extra energy is not used, cell numbers increase in adipose tissue, which then becomes hyperplastic (34). Hyperplastic and hypertrophic adipocytes are often hypoxic, partly explaining the development of inflammation (35). Secondly, hypoxia also induces the production of HIF- $1 \alpha$, which in turn leads to a potent profibrotic transcriptional program with extracellular matrix (ECM) component accumulation, leading to fibrosis and adipose tissue dysfunction $(36,37)$. Concurrently, immune cells infiltrate the adipose tissue, and pro-inflammatory cytokines are overexpressed (33). Under lean conditions, high $\mathrm{M} 2 / \mathrm{M} 1$ ratio, eosinophils, and regulatory $\mathrm{T}$ cells, which secrete IL-4/IL-13 and IL-10, lead to an anti-inflammatory phenotype. In obesity, activation of several stress pathways such as endoplasmic reticulum stress, oxidative stress, and inflammasome (38), but also hypoxia, induces a shift in innate immunity and lymphoid cells and a modification of macrophagic signature with a rapid shift in polarization toward an M1 phenotype, associated with adipose tissue inflammation and insulin resistance $(35,39,40)$. A chronic low-grade inflammation state is therefore mainly explained by immune cell imbalance in dysfunctional adipose tissue. Stressed adipocytes release free fatty acids (FFAs) and secrete chemokines that lead to inflammatory immune cell infiltration secreting pro-inflammatory cytokines (41). Intestinal microbiota dysbiosis can also trigger inflammation by activation of immunesignaling pathways (42). The dysfunction of SAT leads to the release of FFAs to peripheral organs and ectopic fat deposition such as EAT.

\section{Epicardial Adipose Tissue and Cardiovascular Risk}

In the last decade, it has been demonstrated that ectopic fat depots localized around the heart contribute to the pathogenesis of cardiovascular disease, independently of other visceral depots $(43,44)$. EAT is an ectopic fat depot located between the myocardium and the visceral pericardium in close contact with coronary vessels (45). With no fascia separating the tissues, local interaction and cellular crosstalk between myocytes and adipocytes can occur. EAT is an extremely active endocrine organ with a high capacity for releasing and taking up FFAs. It is thought that EAT has protective functions as a mechanical shock absorber against pulse waves, a regulator of FFA homeostasis, and, in a more recent work, a thermogenic factor (46-49). It is a major source of adipokines, chemokines, and cytokines, interacting paracrinally or vasocrinally with vascular cells or myocytes (44). Expression and secretion of pro-inflammatory cytokines (IL-6, IL-1 $\beta$, MCP-1, TNF- $\alpha$, etc.) have been found to be higher in EAT than in subcutaneous fat (50), partly by the upregulation of nuclear factor $\kappa \mathrm{B}(\mathrm{NF}-\mathrm{\kappa B})$ and c-Jun N-terminal kinase (JNK). It was hypothesized to accentuate vascular inflammation, plaque instability via apoptosis (TNF- $\alpha$ ), and neovascularization (MCP-1).

Using a pangenomic and unbiased lipidomic approach, we previously reported that EAT has a specific transcriptomic and lipidomic signature particularly enriched in inflammation, extracellular matrix remodeling, immune signaling, thrombosis, beiging, coagulation, apoptosis, and lipotoxic pathways with an enrichment in ceramides, diglycerides, and monoglycerides compared with SAT, especially in patients with coronary artery disease (CAD) $(47,51)$. Furthermore, we previously demonstrated that human EAT secretome induced marked fibrosis of myocardial atria through the secretion of adipo-fibrokines, such as activin A (52). Activin A was shown to be enhanced in patients with heart failure and reduced ejection fraction and was abundantly expressed in EAT of type 2 diabetes (T2D) patients with obesity (53).

EAT thickness, volume, and density can be assessed by various imaging techniques such as echocardiography (54), computed tomography (CT), and magnetic resonance imaging (55). Higher EAT volume and lower density were associated with coronary calcification and serum levels of plaque inflammatory markers (56). EAT has been shown to be associated with CAD and the occurrence of major adverse cardiovascular events in many studies (57-60). It is correlated with the extent and severity of CAD, chest pain, unstable angina, and coronary flow reserve $(61,62)$ and could be a marker of the atherosclerotic burden even in asymptomatic patients $(63,64)$. EAT may also play a role in the development of atrial fibrillation (AF) (65) by infiltration of adipocytes in the atrial myocardium, mechanical effect on left atrial pressure stretch and wall stress, fibrosis, and inflammation, which can lead to structural and electrical remodeling and cardiac automatic system activation (44).

Obesity thus leads to an increase in ectopic fat deposition, particularly at the epicardial level, which may partly explain the increase in adverse cardiovascular events in this condition. Moreover, the pro-inflammatory phenotype of adipose tissue makes this organ a target for further immune amplification by external pathogens, such as SARS-CoV-2. In the current context of COVID-19 infection, we will see how dysfunction of the adipose tissue leads to a higher risk of severe-form COVID-19.

\section{DYSFUNCTIONAL ADIPOSE TISSUE IN OBESITY: A KEY TO UNDERSTANDING BAD OUTCOMES DURING THE COVID-19 PANDEMIC}

\section{Immune and Metabolic Derangement as a Possible Link to Worse Outcomes in Obesity}

It has been demonstrated that host cell entry of SARS-CoV-2 depending on ACE2 receptors and overexpression of human ACE2 can increase viral infection and replication. Some studies have demonstrated that the expression of ACE2 in adipocytes is higher than that in the lungs, which can act as an important viral reservoir $(7,66)$. Experimental studies on mice showed an increased expression of ACE2 in adipocytes in case of a highfat diet (67). In obesity, excess adipose tissue may thus increase SARS-CoV-2 infection and accessibility to the tissue, leading to 
an increased viral systemic spread, entry, and prolonged viral shedding (68), as seen during the influenza A epidemic. After infection of host cells, the recruitment of pro-inflammatory cytokines and impaired lymphocyte $\mathrm{T}$ cells culminates in a cytokine storm associated with progression to ARDS and multi-organ failure (13). In severe respiratory forms, patients with COVID-19 infection showed macrophage activation syndrome. There is a depletion of lymphocytes CD4 and CD8 (69) but a higher ratio of pro-inflammatory Th17 cells and high secretion of pro-inflammatory cytokines IL-2, IL-6, and TNF- $\alpha$ $(70,71)$. In obesity, dysfunctional hypertrophic adipocytes overproduce pro-inflammatory cytokines, leading to a chronic lowgrade inflammation state. This in turn causes metabolic and immune derangement, making a cytokine storm more likely (72). The dysfunction of an adaptative immune system with increased pro-inflammatory $\mathrm{LTCD}^{+}$and impaired T-cell function could also increase this risk. In this regard, the PD-1/ PDL-1 immune checkpoint could increase within the visceral adipose tissue (VAT) of individuals with obesity. PD-1 is expressed by $\mathrm{T}$ cells and interacts with receptor PDL-1 to inhibit cytotoxic $\mathrm{T}$ cell responses. A recent study showed that $\mathrm{T}$ cells of individuals with obesity increased PD-1 expression, leading to T-cell exhaustion and dysfunction (73). During severe COVID-19, the number of TCD $4^{+}$and $\mathrm{TCD}^{+}$is also reduced, and expression of PD-1 is increased (74). Interestingly, Alzaid et al. observed particularly low levels of cytotoxic CD8 ${ }^{+}$ lymphocytes and increased monocyte size and monocytopenia restricted to classical $\mathrm{CD} 14^{\mathrm{Hi}} \mathrm{CD} 16^{-}$monocytes, which were specifically associated with severe COVID-19 in patients with T2D requiring intensive care (75). Monocyte loss was accompanied by morphological alteration and a hyperinflammatory expression profile consistent with the type 1 interferon pathway (IL-6, IL-8, CCL2, and INFB-1). This particular immunophenotype could be a clue to a better understanding of the increased risk of severe forms in individuals with obesity by the escape of SARS-CoV-2 from lysis.

More recently, a significant increase in IL-1 $\beta$ level in plasma was reported in COVID-19 patients (11), suggesting that the NOD-like receptor family pyrin domain-containing 3 (NLRP3) inflammasome might be involved in the pathogenesis of infection and lung injury. NLRP3 is a multiprotein complex present in macrophages, dendritic cells, and other non-immune cells. The activation of NLRP3 as a pivotal component of the innate immune system plays a critical role in the host defense but is also associated with metabolic and inflammatory conditions (76). During SARS-CoV-2 infection, the intense and rapid stimulation of immune system response could trigger activation of the NLRP3 inflammasome pathway and the release of its products including IL-6 and IL-1 $\beta$ (77), which could be involved in maintaining inflammation. Viral infection could potentiate this underlying systemic inflammatory state, which could partly explain worse outcomes in obese patients (78).

It has also been demonstrated that individuals with obesity display white adipose tissue depot in large airway walls, proportionally to BMI, which could lead to airway thickening, immune cell infiltration, and then tissue damage and fibrosis in the lungs $(79,80)$. Also found in the lungs, lipofibroblasts, adipose-like cells composed of lipid droplets and located in the alveolar interstitium, could transdifferentiate to myofibroblasts and lead to pulmonary fibrosis $(5,7)$.

There would then be a higher expression of ACE2 and TMPRSS2 in lung epithelial cells from individuals with obesity than in those without, as demonstrated in vitro (81).

These conditions could be another basis for the elevated occurrence of ARDS in obese individuals with obesity.

These different elements partly explain the role of adipose visceral tissue in critical COVID-19 infection, as a viral reservoir and by increasing immune responses with consequences for cytokine cascade amplification and severe forms of the disease. VAT and EAT could be markers of severity, and recent studies also show that it could be implicated in myocardial injury.

\section{Visceral Adipose Tissue and Epicardial Adipose Tissue as Markers of Myocardial Injury}

Cardiac complications have been reported in 28\% of patients hospitalized for COVID-19 infection (3, 82, 83). Myocardial injury and myocarditis with elevated troponin occurs in $7 \%-17 \%$ of hospitalized patients and are associated with an increased risk of adverse outcomes $(84,85)$. Acute myocarditis represents a significant diagnostic challenge because of its varied clinical presentations and risk of worse outcomes such as heart failure. Changes in electrocardiograms, elevated cardiac biomarkers, and impaired cardiac function should be considered as alerts pointing to acute myocarditis (86). Remarkably, no culprit injury was found in $40 \%$ of patients with COVID-19 presenting ST-elevation myocardial infarction (87), which could be promoted by hypercoagulability, endothelial dysfunction, microvascular damage, hypoxia-induced injury, myocarditis, or systemic inflammatory cytokine storm syndrome. In several studies, cardiac troponin I level was found to be associated with more severe disease and mortality, making myocardial damage a prognostic factor $(88,89)$. Furthermore, dysrhythmias linked to hypoxia, inflammatory stress, and therapeutics affect up to $17 \%$ of hospitalized patients $(90,91)$. Finally, some studies report that heart failure may be present in $23 \%$ of patients hospitalized for COVID-19, half of whom had no history of hypertension or cardiovascular disease.

The mechanisms of these cardiac events are not fully clarified, and ectopic fat and EAT could be important triggers of their development. More than just BMI, several reports have shown that VAT volume measured by CT is associated with critical illness in patients with COVID-19 entailing hospitalization (92), intensive care need, or death (93-96). According to Favre et al., a visceral fat area $\geq 128.5 \mathrm{~cm}^{2}$ was the best predictive value for severe COVID-19 (93). Further, EAT, known to be strongly correlated with VAT, has been associated with the occurrence of cardiac events in COVID-19 infection.

CT imaging of the EAT allows adipose tissue inflammation to be characterized by quantifying CT threshold attenuation. 
The group of Iacobellis showed that density of EAT, reflecting inflammatory changes, significantly increased with increasing COVID-19 severity compared to discharged patients (97). Furthermore, EAT mean attenuation was negatively correlated to high-sensitivity troponin $\mathrm{T}$ levels and peripheral oxygen saturation (97). Another international multicenter study on 109 patients showed that volume and attenuation of EAT measured by CT was associated with extent of pneumonia and were independent predictors of clinical deterioration or death (98). This study used a fully automated three-dimensional measurement of EAT and demonstrated that EAT volume can predict clinical deterioration or death independently of clinical factors such as age, diabetes, hypertension, or smoking history (99). This suggests the importance of automated measurement of EAT for COVID-19 risk stratification. An increased EAT volume was associated with lung dysfunction even in healthy individuals (100), and the close proximity of EAT to the pulmonary circulation could enable direct diffusion of inflammatory mediators. According to Wei et al., EAT volume appeared to be an independent predictor of myocardial injury in patients with COVID-19 $(\mathrm{OR}=3.06)$ with a maximal cutoff value of $137.1 \mathrm{~cm}^{2}$ (89) after adjustment for age, weight, history of cardiovascular disease, and dyslipidemia. This work performed in a large cohort of 400 patients from six Chinese hospitals clearly indicates that EAT volume enlargement may predict the development of myocardial injury. However, the cutoff needs to be evaluated in ethnically diverse cohorts. Furthermore, EAT was significantly higher in severe cases of COVID-19 groups, i.e., with signs of respiratory distress (101). In a recent study, Iacobellis et al. showed that on 427 infected patients, use of dexamethasone reduced EAT attenuation (102). EAT could therefore also serve as a therapeutic target for antiinflammatory treatment. All these studies indicate that EAT volume and inflammation itself are associated with COVID-19 severity and adverse cardiac events.

The mechanisms of these cardiac events are not fully elucidated, and EAT could be a clue to understanding them. First, epicardial fat cells seemed to express higher levels of ACE2 than subcutaneous fat cells, which could make them a viral reservoir in COVID-19 infection. A study on EAT and SAT biopsies from 43 patients who underwent open-heart surgery identified higher levels of ACE2 $(p<0.05)$ but lower ADAM-17 $(p<0.001)$, with its cleavage enzyme in EAT compared with subcutaneous fat. Obesity and T2D exacerbated this difference in patients with cardiovascular disease (103). In an animal study, ACE2 was upregulated in murine EAT in association with highfat diet. Loss of ACE2 in knock-out diet-induced-obesity (ACE2KO-DIO) mice increased macrophage polarization to a pro-inflammatory phenotype and EAT inflammation compared with wild-type and control diet mice. The same study showed that in human EAT from obese patients with heart failure, ACE2 was increased and was also associated with pro-inflammatory macrophage phenotype compared with lean patients $(104,105)$. Voluminous and hypervascularized EAT in individuals with obesity could facilitate viral spread, immune response, and greater pro-inflammatory cytokine secretion. Volume of EAT was positively correlated with inflammatory biomarkers during COVID-19 infection in a study of 100 patients (106), with a significant positive mild association with neutrophil-tolymphocyte ratio $(r=0.33, p=0.001)$ and platelet-to-

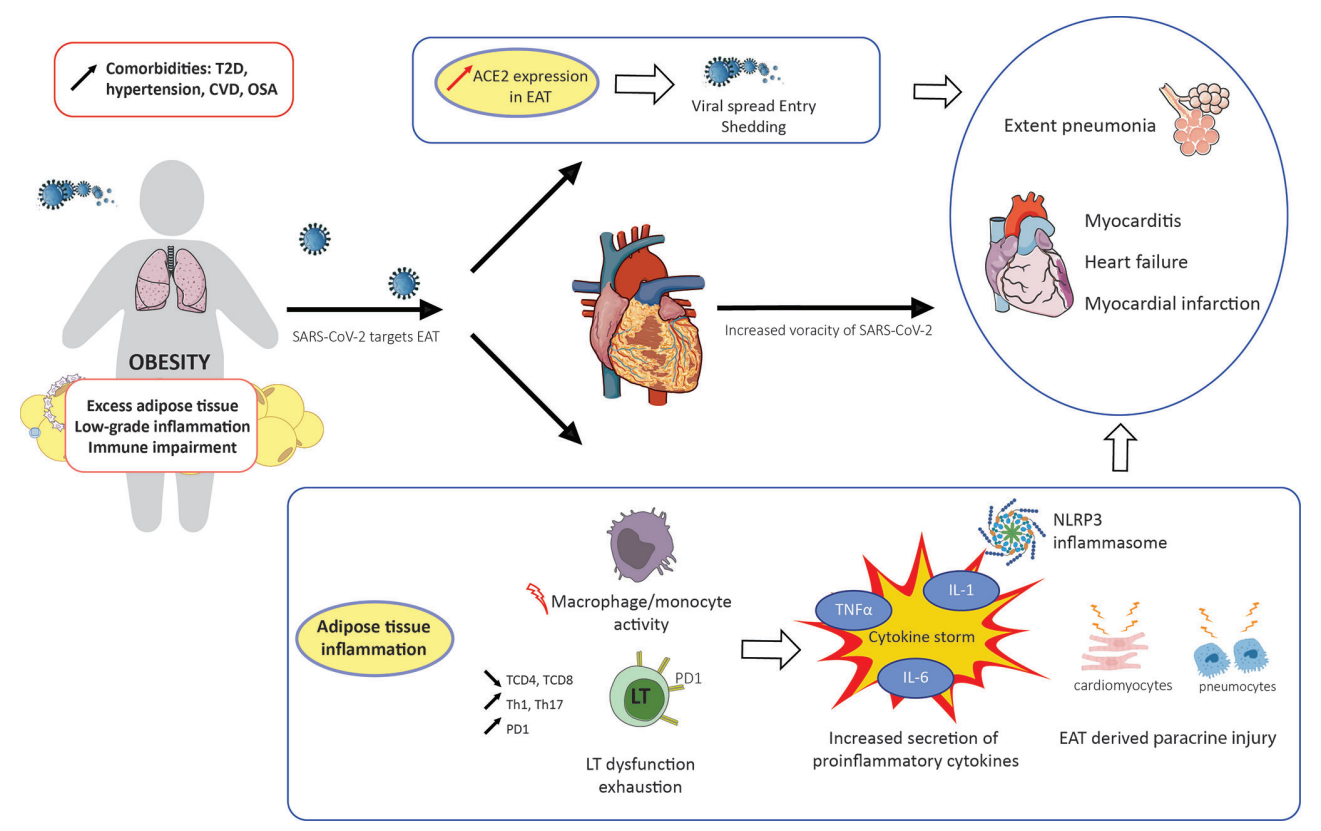

FIGURE 1 | Impact of obesity and inflammation of epicardial adipose tissue on COVID-19 outcome. CVD, cardiovascular disease; EAT, epicardial adipose tissue; OSA, obstructive sleep apnea; T2D, type 2 diabetes. 
lymphocyte ratio $(r=0.25, p=0.01)$ but a negative correlation with lymphocyte-to-C-reactive protein (CRP) ratio $(r=-0.25$, $p=0.02$ ). Pro-inflammatory cytokines such as TNF- $\alpha$ and IL-6 are expressed at higher levels in EAT of individuals with obesity linked to a reduction of inotropic effect and cardiac function resulting in hypoxia and systemic myocardial inflammatory response (43). By taking advantage of more ACE2-binding sites, which ultimately lead to an augmented inflammatory signaling cascade, EAT inflammation could contribute to myocardial complications, such as myocarditis or cardiomyocyte dysfunction (107), and then heart failure. Furthermore, it has recently been shown that EAT adipocytes can release exosomes that can enter cardiac cells via endocytosis (105). This suggests numerous mechanisms by which EAT could impair cardiac function, particularly via the transfer of microRNAs from EAT to the myocardium and could help mediate SARS-CoV-2 entry into the heart, causing direct cardiac effects.

COVID-19 thus induces an immune-mediated inflammatory response, and EAT may transduce this inflammation to the heart. It can be implicated in COVID-19 myocarditis by its contiguity with the myocardium and its pro-inflammatory secretome reaching the myo-pericardium directly by the vasa vasorum and paracrinally (108-110).

EAT thus contributes to bad outcomes during COVID-19 infection. We and others have shown that EAT significantly responds to drugs targeting the fat (44). EAT not only is a marker of inflammation, but it can be a target to anti-inflammatory treatment. Further studies on the impact of COVID treatment on EAT volume and inflammation are needed.

All these elements are summarized in Figure 1.

\section{REFERENCES}

1. Guan W-J, Ni Z-Y, Hu Y, Liang W-H, Ou C-Q, He J-X, et al. Clinical Characteristics of Coronavirus Disease 2019 in China. N Engl J Med (2020) 382:1708-20. doi: 10.1056/NEJMoa2002032

2. Wu Z, McGoogan JM. Characteristics of and Important Lessons From the Coronavirus Disease 2019 (COVID-19) Outbreak in China: Summary of a Report of 72314 Cases From the Chinese Center for Disease Control and Prevention. JAMA (2020) 323:1239-42. doi: 10.1001/jama.2020.2648

3. Guo T, Fan Y, Chen M, Wu X, Zhang L, He T, et al. Cardiovascular Implications of Fatal Outcomes of Patients With Coronavirus Disease 2019 (COVID-19). JAMA Cardiol (2020) 5:1-8. doi: 10.1001/jamacardio.2020.1017

4. Hoffmann M, Kleine-Weber H, Schroeder S, Krüger N, Herrler T, Erichsen S, et al. SARS-CoV-2 Cell Entry Depends on ACE2 and TMPRSS2 and Is Blocked by a Clinically Proven Protease Inhibitor. Cell (2020) 181:27180.e8. doi: 10.1016/j.cell.2020.02.052

5. Pasquarelli-do-Nascimento G, Braz-de-Melo HA, Faria SS, Santos I de O, Kobinger GP, Magalhães KG. Hypercoagulopathy and Adipose Tissue Exacerbated Inflammation May Explain Higher Mortality in COVID-19 Patients With Obesity. Front Endocrinol (Lausanne) (2020) 11:530. doi: 10.3389/fendo.2020.00530

6. Zou X, Chen K, Zou J, Han P, Hao J, Han Z. Single-Cell RNA-Seq Data Analysis on the Receptor ACE2 Expression Reveals the Potential Risk of Different Human Organs Vulnerable to 2019-Ncov Infection. Front Med (2020) 14(2):185-92. doi: 10.1007/s11684-020-0754-0

7. Kruglikov IL, Scherer PE. The Role of Adipocytes and Adipocyte-Like Cells in the Severity of COVID-19 Infections. Obes (Silver Spring) (2020) 28:118790. doi: 10.1002/oby.22856

\section{CONCLUSION}

Obesity is a major risk factor for COVID-19. Identifying patients with obesity who are at high risk of ICU need is crucial. Multiple studies have demonstrated that ectopic fat accumulation, especially EAT, is a major driver of COVID-19 severity in such patients. This unique potentially inflamed EAT depot may play a direct role in COVID-19 cardiac injury, acting as a fuel through its specific anatomical contact with the myocardium and its inflammatory status. Large studies with systematic evaluation of EAT volume and CT scan attenuation together with evaluation of pulmonary involvement are needed. Deep learning algorithms leading to new fully automated three-dimensional methods for the measurement of EAT will help improve clinical risk stratification.

\section{AUTHOR CONTRIBUTIONS}

Conceptualization, $\mathrm{AD}$ and $\mathrm{BG}$. Writing-original draft preparation, $\mathrm{AL}, \mathrm{AB}, \mathrm{PA}, \mathrm{AS}, \mathrm{AD}$, and $\mathrm{BG}$. Writing-review and editing, AJ, AD, and BG. Supervision, AD and BG. All authors contributed to the article and approved the submitted version.

\section{FUNDING}

GIRCI (Groupement interrégional de recherche clinique et d'innovation) Méditerranée VALO-DATA 2020.

8. Müller JA, Groß R, Conzelmann C, Krüger J, Merle U, Steinhart J, et al SARS-CoV-2 Infects and Replicates in Cells of the Human Endocrine and Exocrine Pancreas. Nat Metab (2021) 3:149-65. doi: 10.1038/s42255-02100347-1

9. Yang X-H, Deng W, Tong Z, Liu Y-X, Zhang L-F, Zhu H, et al. Mice Transgenic for Human Angiotensin-Converting Enzyme 2 Provide a Model for SARS Coronavirus Infection. Comp Med (2007) 57:450-9.

10. Zhou P, Yang X-L, Wang X-G, Hu B, Zhang L, Zhang W, et al. A Pneumonia Outbreak Associated With a New Coronavirus of Probable Bat Origin. Nature (2020) 579:270-3. doi: 10.1038/s41586-020-2012-7

11. Huang C, Wang Y, Li X, Ren L, Zhao J, Hu Y, et al. Clinical Features of Patients Infected With 2019 Novel Coronavirus in Wuhan, China. Lancet (2020) 395:497-506. doi: 10.1016/S0140-6736(20)30183-5

12. Fajgenbaum DC, June CH. Cytokine Storm. N Engl J Med (2020) 383:225573. doi: 10.1056/NEJMra2026131

13. Mehta P, McAuley DF, Brown M, Sanchez E, Tattersall RS, Manson JJ. HLH Across Speciality Collaboration, UK. COVID-19: Consider Cytokine Storm Syndromes and Immunosuppression. Lancet (2020) 395:1033-4. doi: 10.1016/S0140-6736(20)30628-0

14. Ulhaq ZS, Soraya GV. Interleukin-6 as a Potential Biomarker of COVID-19 Progression. Med Mal Infect (2020) 50:382-3. doi: 10.1016/j.medmal. 2020.04.002

15. Falagas ME, Kompoti M. Obesity and Infection. Lancet Infect Dis (2006) 6:438-46. doi: 10.1016/S1473-3099(06)70523-0

16. Frydrych LM, Bian G, O'Lone DE, Ward PA, Delano MJ. Obesity and Type 2 Diabetes Mellitus Drive Immune Dysfunction, Infection Development, and Sepsis Mortality. J Leukoc Biol (2018) 104:525-34. doi: 10.1002/ JLB.5VMR0118-021RR 
17. Van Kerkhove MD, Vandemaele KAH, Shinde V, Jaramillo-Gutierrez G, Koukounari A, Donnelly CA, et al. Risk Factors for Severe Outcomes Following 2009 Influenza A (H1N1) Infection: A Global Pooled Analysis. PloS Med (2011) 8:e1001053. doi: 10.1371/journal.pmed.1001053

18. Díaz E, Rodríguez A, Martin-Loeches I, Lorente L, Del Mar Martín M, Pozo JC, et al. Impact of Obesity in Patients Infected With 2009 Influenza a (H1N1). Chest (2011) 139:382-6. doi: 10.1378/chest.10-1160

19. Zheng Z, Peng F, Xu B, Zhao J, Liu H, Peng J, et al. Risk Factors of Critical \& Mortal COVID-19 Cases: A Systematic Literature Review and MetaAnalysis. J Infect (2020) 81:e16-25. doi: 10.1016/j.jinf.2020.04.021

20. Zhou Y, Chi J, Lv W, Wang Y. Obesity and Diabetes as High-Risk Factors for Severe Coronavirus Disease 2019 (Covid-19). Diabetes Metab Res Rev (2020) 37(2):e3377. doi: 10.1002/dmrr.3377

21. Pietri L, Giorgi R, Bégu A, Lojou M, Koubi M, Cauchois R, et al. Excess Body Weight Is an Independent Risk Factor for Severe Forms of COVID-19. Metabolism (2021) 117:154703. doi: 10.1016/j.metabol.2021.154703

22. Richardson S, Hirsch JS, Narasimhan M, Crawford JM, McGinn T, Davidson KW, et al. Presenting Characteristics, Comorbidities, and Outcomes Among 5700 Patients Hospitalized With COVID-19 in the New York City Area. JAMA (2020) 323:2052-9. doi: 10.1001/jama.2020.6775

23. Popkin BM, Du S, Green WD, Beck MA, Algaith T, Herbst CH, et al. Individuals With Obesity and COVID-19: A Global Perspective on the Epidemiology and Biological Relationships. Obes Rev (2020) 21:e13128. doi: $10.1111 /$ obr.13128

24. Huang Y, Lu Y, Huang Y-M, Wang M, Ling W, Sui Y, et al. Obesity in Patients With COVID-19: A Systematic Review and Meta-Analysis. Metabolism (2020) 113:154378. doi: 10.1016/j.metabol.2020.154378

25. Simonnet A, Chetboun M, Poissy J, Raverdy V, Noulette J, Duhamel A, et al. High Prevalence of Obesity in Severe Acute Respiratory Syndrome Coronavirus-2 (SARS-CoV-2) Requiring Invasive Mechanical Ventilation. Obes (Silver Spring) (2020) 28:1195-9. doi: 10.1002/oby.22831

26. Anderson MR, Geleris J, Anderson DR, Zucker J, Nobel YR, Freedberg D, et al. Body Mass Index and Risk for Intubation or Death in SARS-CoV-2 Infection. Ann Intern Med (2020) 174(6):886. doi: 10.7326/M20-3214

27. Kass DA, Duggal P, Cingolani O. Obesity Could Shift Severe COVID-19 Disease to Younger Ages. Lancet (2020) 395:1544-5. doi: 10.1016/S01406736(20)31024-2

28. Smati S, Tramunt B, Wargny M, Caussy C, Gaborit B, Vatier C, et al. Relationship Between Obesity and Severe COVID-19 Outcomes in Patients With Type 2 Diabetes: Results From the CORONADO Study. Diabetes Obes Metab (2021) 23:391-403. doi: 10.1111/dom.14228

29. Cariou B, Hadjadj S, Wargny M, Pichelin M, Al-Salameh A, Allix I, et al. Phenotypic Characteristics and Prognosis of Inpatients With COVID-19 and Diabetes: The CORONADO Study. Diabetologia (2020) 63:1500-15. doi: 10.1007/s00125-020-05180-x

30. Czernichow S, Beeker N, Rives-Lange C, Guerot E, Diehl J-L, Katsahian S, et al. Obesity Doubles Mortality in Patients Hospitalized for Severe Acute Respiratory Syndrome Coronavirus 2 in Paris Hospitals, France: A Cohort Study on 5,795 Patients. Obes (Silver Spring) (2020) 28:2282-9. doi: 10.1002/oby.23014

31. Després J-P, Lemieux I. Abdominal Obesity and Metabolic Syndrome. Nature (2006) 444:881-7. doi: 10.1038/nature05488

32. Després J-P. Body Fat Distribution and Risk of Cardiovascular Disease: An Update. Circulation (2012) 126:1301-13. doi: 10.1161/CIRCULATIONAHA.111.067264

33. Unamuno X, Gómez-Ambrosi J, Rodríguez A, Becerril S, Frühbeck G, Catalán V. Adipokine Dysregulation and Adipose Tissue Inflammation in Human Obesity. Eur J Clin Invest (2018) 48:e12997. doi: 10.1111/eci.12997

34. Haczeyni F, Bell-Anderson KS, Farrell GC. Causes and Mechanisms of Adipocyte Enlargement and Adipose Expansion. Obes Rev (2018) 19:406-20. doi: 10.1111/obr.12646

35. Castoldi A, Naffah de Souza C, Câmara NOS, Moraes-Vieira PM. The Macrophage Switch in Obesity Development. Front Immunol (2015) 6:637. doi: 10.3389/fimmu.2015.00637

36. Sun K, Tordjman J, Clément K, Scherer PE. Fibrosis and Adipose Tissue Dysfunction. Cell Metab (2013) 18:470-7. doi: 10.1016/j.cmet.2013.06.016

37. Divoux A, Clement K. Architecture and the Extracellular Matrix: The Still Unappreciated Components of the Adipose Tissue. Obes Rev (2011) 12: e494-503. doi: 10.1111/j.1467-789X.2010.00811.x
38. Hotamisligil GS. Endoplasmic Reticulum Stress and the Inflammatory Basis of Metabolic Disease. Cell (2010) 140:900-17. doi: 10.1016/j.cell.2010.02.034

39. Lumeng CN, Bodzin JL, Saltiel AR. Obesity Induces a Phenotypic Switch in Adipose Tissue Macrophage Polarization. J Clin Invest (2007) 117:175-84. doi: 10.1172/JCI29881

40. Dalmas E, Clément K, Guerre-Millo M. Defining Macrophage Phenotype and Function in Adipose Tissue. Trends Immunol (2011) 32:307-14. doi: 10.1016/j.it.2011.04.008

41. Xu L, Kitade H, Ni Y, Ota T. Roles of Chemokines and Chemokine Receptors in Obesity-Associated Insulin Resistance and Nonalcoholic Fatty Liver Disease. Biomolecules (2015) 5:1563-79. doi: 10.3390/biom5031563

42. Cox AJ, West NP, Cripps AW. Obesity, Inflammation, and the Gut Microbiota. Lancet Diabetes Endocrinol (2015) 3:207-15. doi: 10.1016/ S2213-8587(14)70134-2

43. Iacobellis G. Local and Systemic Effects of the Multifaceted Epicardial Adipose Tissue Depot. Nat Rev Endocrinol (2015) 11:363-71. doi: $10.1038 /$ nrendo. 2015.58

44. Gaborit B, Sengenes C, Ancel P, Jacquier A, Dutour A. Role of Epicardial Adipose Tissue in Health and Disease: A Matter of Fat? Compr Physiol (2017) 7:1051-82. doi: 10.1002/cphy.c160034

45. Iacobellis G, Bianco AC. Epicardial Adipose Tissue: Emerging Physiological, Pathophysiological and Clinical Features. Trends Endocrinol Metab (2011) 22:450-7. doi: 10.1016/j.tem.2011.07.003

46. Rabkin SW. Epicardial Fat: Properties, Function and Relationship to Obesity. Obes Rev (2007) 8:253-61. doi: 10.1111/j.1467-789X.2006.00293.x

47. Gaborit B, Venteclef N, Ancel P, Pelloux V, Gariboldi V, Leprince P, et al. Human Epicardial Adipose Tissue has a Specific Transcriptomic Signature Depending on Its Anatomical Peri-Atrial, Peri-Ventricular, or PeriCoronary Location. Cardiovasc Res (2015) 108:62-73. doi: 10.1093/cvr/ crv208

48. Silaghi A, Achard V, Paulmyer-Lacroix O, Scridon T, Tassistro V, Duncea I, et al. Expression of Adrenomedullin in Human Epicardial Adipose Tissue: Role of Coronary Status. Am J Physiol Endocrinol Metab (2007) 293:E144350. doi: 10.1152/ajpendo.00273.2007

49. Sacks HS, Fain JN, Bahouth SW, Ojha S, Frontini A, Budge H, et al. Adult Epicardial Fat Exhibits Beige Features. J Clin Endocrinol Metab (2013) 98: E1448-55. doi: 10.1210/jc.2013-1265

50. Mazurek T, Zhang L, Zalewski A, Mannion JD, Diehl JT, Arafat H, et al. Human Epicardial Adipose Tissue Is a Source of Inflammatory Mediators. Circulation (2003) 108:2460-6. doi: 10.1161/01.CIR.0000099542.57313.C5

51. Barchuk M, Dutour A, Ancel P, Svilar L, Miksztowicz V, Lopez G, et al. Untargeted Lipidomics Reveals a Specific Enrichment in Plasmalogens in Epicardial Adipose Tissue and a Specific Signature in Coronary Artery Disease. Arterioscler Thromb Vasc Biol (2020) 40:986-1000. doi: 10.1161/ ATVBAHA.120.313955

52. Venteclef N, Guglielmi V, Balse E, Gaborit B, Cotillard A, Atassi F, et al. Human Epicardial Adipose Tissue Induces Fibrosis of the Atrial Myocardium Through the Secretion of Adipo-Fibrokines. Eur Heart $J$ (2015) 36:795-805a. doi: 10.1093/eurheartj/eht099

53. Greulich S, Maxhera B, Vandenplas G, de Wiza DH, Smiris K, Mueller H, et al. Secretory Products From Epicardial Adipose Tissue of Patients With Type 2 Diabetes Mellitus Induce Cardiomyocyte Dysfunction. Circulation (2012) 126:2324-34. doi: 10.1161/CIRCULATIONAHA.111.039586

54. Iacobellis G, Assael F, Ribaudo MC, Zappaterreno A, Alessi G, Di Mario U, et al. Epicardial Fat From Echocardiography: A New Method for Visceral Adipose Tissue Prediction. Obes Res (2003) 11:304-10. doi: 10.1038/ oby. 2003.45

55. Mahajan R, Kuklik P, Grover S, Brooks AG, Wong CX, Sanders P, et al. Cardiovascular Magnetic Resonance of Total and Atrial Pericardial Adipose Tissue: A Validation Study and Development of a 3 Dimensional Pericardial Adipose Tissue Model. J Cardiovasc Magn Reson (2013) 15:73. doi: 10.1186/ 1532-429X-15-73

56. Goeller M, Achenbach S, Marwan M, Doris MK, Cadet S, Commandeur F, et al. Epicardial Adipose Tissue Density and Volume Are Related to Subclinical Atherosclerosis, Inflammation and Major Adverse Cardiac Events in Asymptomatic Subjects. J Cardiovasc Comput Tomogr (2018) 12:67-73. doi: 10.1016/j.jcct.2017.11.007 
57. Mancio J, Azevedo D, Saraiva F, Azevedo AI, Pires-Morais G, Leite-Moreira A, et al. Epicardial Adipose Tissue Volume Assessed by Computed Tomography and Coronary Artery Disease: A Systematic Review and Meta-Analysis. Eur Heart J Cardiovasc Imaging (2018) 19:490-7. doi: 10.1093/ehjci/jex314

58. Greif M, Becker A, von Ziegler F, Lebherz C, Lehrke M, Broedl UC, et al. Pericardial Adipose Tissue Determined by Dual Source CT Is a Risk Factor for Coronary Atherosclerosis. Arterioscler Thromb Vasc Biol (2009) 29:7816. doi: 10.1161/ATVBAHA.108.180653

59. Mohar DS, Salcedo J, Hoang KC, Kumar S, Saremi F, Erande AS, et al. Epicardial Adipose Tissue Volume as a Marker of Coronary Artery Disease Severity in Patients With Diabetes Independent of Coronary Artery Calcium: Findings From the CTRAD Study. Diabetes Res Clin Pract (2014) 106:228-35. doi: 10.1016/j.diabres.2014.08.021

60. Spearman JV, Renker M, Schoepf UJ, Krazinski AW, Herbert TL, De Cecco $\mathrm{CN}$, et al. Prognostic Value of Epicardial Fat Volume Measurements by Computed Tomography: A Systematic Review of the Literature. Eur Radiol (2015) 25:3372-81. doi: 10.1007/s00330-015-3765-5

61. Otaki Y, Hell M, Slomka PJ, Schuhbaeck A, Gransar H, Huber B, et al. Relationship of Epicardial Fat Volume From Noncontrast CT With Impaired Myocardial Flow Reserve by Positron Emission Tomography. J Cardiovasc Comput Tomogr (2015) 9:303-9. doi: 10.1016/j.jcct.2015.03.005

62. Sade LE, Eroglu S, Bozbaş H, Ozbiçer S, Hayran M, Haberal A, et al. Relation Between Epicardial Fat Thickness and Coronary Flow Reserve in Women With Chest Pain and Angiographically Normal Coronary Arteries. Atherosclerosis (2009) 204:580-5. doi: 10.1016/j.atherosclerosis.2008.09.038

63. Yerramasu A, Dey D, Venuraju S, Anand DV, Atwal S, Corder R, et al. Increased Volume of Epicardial Fat Is an Independent Risk Factor for Accelerated Progression of Sub-Clinical Coronary Atherosclerosis. Atherosclerosis (2012) 220:223-30. doi: 10.1016/j.atherosclerosis.2011.09.041

64. Bachar GN, Dicker D, Kornowski R, Atar E. Epicardial Adipose Tissue as a Predictor of Coronary Artery Disease in Asymptomatic Subjects. Am J Cardiol (2012) 110:534-8. doi: 10.1016/j.amjcard.2012.04.024

65. Friedman DJ, Wang N, Meigs JB, Hoffmann U, Massaro JM, Fox CS, et al. Pericardial Fat Is Associated With Atrial Conduction: The Framingham Heart Study. J Am Heart Assoc (2014) 3:e000477. doi: 10.1161/ JAHA.113.000477

66. Al-Benna S. Association of High Level Gene Expression of ACE2 in Adipose Tissue With Mortality of COVID-19 Infection in Obese Patients. Obes Med (2020) 19:100283. doi: 10.1016/j.obmed.2020.100283

67. Gupte M, Boustany-Kari CM, Bharadwaj K, Police S, Thatcher S, Gong MC, et al. ACE2 Is Expressed in Mouse Adipocytes and Regulated by a High-Fat Diet. Am J Physiol Regul Integr Comp Physiol (2008) 295:R781-788. doi: 10.1152/ajpregu.00183.2008

68. Maier HE, Lopez R, Sanchez N, Ng S, Gresh L, Ojeda S, et al. Obesity Increases the Duration of Influenza A Virus Shedding in Adults. J Infect Dis (2018) 218:1378-82. doi: 10.1093/infdis/jiy370

69. Qin C, Zhou L, Hu Z, Zhang S, Yang S, Tao Y, et al. Dysregulation of Immune Response in Patients With COVID-19 in Wuhan, China. Clin Infect Dis (2020) (15):762-8. doi: 10.1093/cid/ciaa248

70. Giamarellos-Bourboulis EJ, Netea MG, Rovina N, Akinosoglou K, Antoniadou A, Antonakos N, et al. Complex Immune Dysregulation in COVID-19 Patients With Severe Respiratory Failure. Cell Host Microbe (2020) 27:992-1000.e3. doi: 10.1016/j.chom.2020.04.009

71. Chen G, Wu D, Guo W, Cao Y, Huang D, Wang H, et al. Clinical and Immunological Features of Severe and Moderate Coronavirus Disease 2019. J Clin Invest (2020) 130:2620-9. doi: 10.1172/JCI137244

72. Mirsoian A, Bouchlaka MN, Sckisel GD, Chen M, Pai C-CS, Maverakis E, et al. Adiposity Induces Lethal Cytokine Storm After Systemic Administration of Stimulatory Immunotherapy Regimens in Aged Mice. J Exp Med (2014) 211:2373-83. doi: 10.1084/jem.20140116

73. Wang Z, Aguilar EG, Luna JI, Dunai C, Khuat LT, Le CT, et al. Paradoxical Effects of Obesity on T Cell Function During Tumor Progression and PD-1 Checkpoint Blockade. Nat Med (2019) 25:141-51. doi: 10.1038/s41591-0180221-5

74. Diao B, Wang C, Tan Y, Chen X, Liu Y, Ning L, et al. Reduction and Functional Exhaustion of T Cells in Patients With Coronavirus Disease 2019 (COVID-19). Front Immunol (2020) 11:827. doi: 10.3389/fimmu.2020.00827
75. Alzaid F, Julla J-B, Diedisheim M, Potier C, Potier L, Velho G, et al. Monocytopenia, Monocyte Morphological Anomalies and Hyperinflammation Characterise Severe COVID-19 in Type 2 Diabetes. EMBO Mol Med (2020) 12:e13038. doi: 10.15252/emmm.202013038

76. López-Reyes A, Martinez-Armenta C, Espinosa-Velázquez R, VázquezCárdenas P, Cruz-Ramos M, Palacios-Gonzalez B, et al. NLRP3 Inflammasome: The Stormy Link Between Obesity and COVID-19. Front Immunol (2020) 11:570251. doi: 10.3389/fimmu.2020.570251

77. Freeman TL, Swartz TH. Targeting the NLRP3 Inflammasome in Severe COVID-19. Front Immunol (2020) 11:1518. doi: 10.3389/fimmu.2020.01518

78. Barra NG, Henriksbo BD, Anhê FF, Schertzer JD. The NLRP3 Inflammasome Regulates Adipose Tissue Metabolism. Biochem J (2020) 477:1089-107. doi: 10.1042/BCJ20190472

79. Elliot JG, Donovan GM, Wang KCW, Green FHY, James AL, Noble PB. Fatty Airways: Implications for Obstructive Disease. Eur Respir J (2019) 54 (6):1900857. doi: 10.1183/13993003.00857-2019

80. Kruger P, Saffarzadeh M, Weber ANR, Rieber N, Radsak M, von Bernuth H, et al. Neutrophils: Between Host Defence, Immune Modulation, and Tissue Injury. PloS Pathog (2015) 11:e1004651. doi: 10.1371/journal.ppat.1004651

81. Al Heialy S, Hachim MY, Senok A, Gaudet M, Abou Tayoun A, Hamoudi R, et al. Regulation of Angiotensin- Converting Enzyme 2 in Obesity: Implications for COVID-19. Front Physiol (2020) 11:555039. doi: 10.3389/ fphys.2020.555039

82. Katz JN, Sinha SS, Alviar CL, Dudzinski DM, Gage A, Brusca SB, et al. COVID-19 and Disruptive Modifications to Cardiac Critical Care Delivery: JACC Review Topic of the Week. J Am Coll Cardiol (2020) 76:72-84. doi: 10.1016/j.jacc.2020.04.029

83. Long B, Brady WJ, Koyfman A, Gottlieb M. Cardiovascular Complications in COVID-19. Am J Emerg Med (2020) 38:1504-7. doi: 10.1016/j.ajem.2020.04.048

84. Chen C, Zhou Y, Wang DW. SARS-CoV-2: A Potential Novel Etiology of Fulminant Myocarditis. Herz (2020) 45(3):230-2. doi: 10.1007/s00059-02004909-Z

85. Zhou F, Yu T, Du R, Fan G, Liu Y, Liu Z, et al. Clinical Course and Risk Factors for Mortality of Adult Inpatients With COVID-19 in Wuhan, China: A Retrospective Cohort Study. Lancet (2020) 395:1054-62. doi: 10.1016/ S0140-6736(20)30566-3

86. Siripanthong B, Nazarian S, Muser D, Deo R, Santangeli P, Khanji MY, et al. Recognizing COVID-19-Related Myocarditis: The Possible Pathophysiology and Proposed Guideline for Diagnosis and Management. Heart Rhythm (2020) 17:1463-71. doi: 10.1016/j.hrthm.2020.05.001

87. Stefanini GG, Montorfano M, Trabattoni D, Andreini D, Ferrante G, Ancona M, et al. ST-Elevation Myocardial Infarction in Patients With COVID-19: Clinical and Angiographic Outcomes. Circulation (2020) 141:2113-6. doi: 10.1161/CIRCULATIONAHA.120.047525

88. Tersalvi G, Vicenzi M, Calabretta D, Biasco L, Pedrazzini G, Winterton D. Elevated Troponin in Patients With Coronavirus Disease 2019: Possible Mechanisms. J Card Fail (2020) 26:470-5. doi: 10.1016/j.cardfail.2020.04.009

89. Wei Z-Y, Qiao R, Chen J, Huang J, Wang W-J, Yu H, et al. Pre-Existing Health Conditions and Epicardial Adipose Tissue Volume: Potential Risk Factors for Myocardial Injury in COVID-19 Patients. Front Cardiovasc Med (2020) 7:585220. doi: 10.3389/fcvm.2020.585220

90. Chen T, Wu D, Chen H, Yan W, Yang D, Chen G, et al. Clinical Characteristics of 113 Deceased Patients With Coronavirus Disease 2019: Retrospective Study. BMJ (2020) 368:m1091. doi: 10.1136/bmj.m1091

91. Driggin E, Madhavan MV, Bikdeli B, Chuich T, Laracy J, Biondi-Zoccai G, et al. Cardiovascular Considerations for Patients, Health Care Workers, and Health Systems During the COVID-19 Pandemic. J Am Coll Cardiol (2020) 75:2352-71. doi: 10.1016/j.jacc.2020.03.031

92. Chandarana H, Dane B, Mikheev A, Taffel MT, Feng Y, Rusinek H. Visceral Adipose Tissue in Patients With COVID-19: Risk Stratification for Severity. Abdom Radiol (NY) (2021) 46:818-25. doi: 10.1007/s00261-020-02693-2

93. Favre G, Legueult K, Pradier C, Raffaelli C, Ichai C, Iannelli A, et al. Visceral Fat Is Associated to the Severity of COVID-19. Metabolism (2021) 115:154440. doi: 10.1016/j.metabol.2020.154440

94. Pediconi F, Rizzo V, Schiaffino S, Cozzi A, Della Pepa G, Galati F, et al. Visceral Adipose Tissue Area Predicts Intensive Care Unit Admission in COVID-19 Patients. Obes Res Clin Pract (2021) 15:89-92. doi: 10.1016/j.orcp.2020.12.002 
95. Watanabe M, Caruso D, Tuccinardi D, Risi R, Zerunian M, Polici M, et al. Visceral Fat Shows the Strongest Association With the Need of Intensive Care in Patients With COVID-19. Metabolism (2020) 111:154319. doi: 10.1016/j.metabol.2020.154319

96. Petersen A, Bressem K, Albrecht J, Thieß H-M, Vahldiek J, Hamm B, et al. The Role of Visceral Adiposity in the Severity of COVID-19: Highlights From a Unicenter Cross-Sectional Pilot Study in Germany. Metabolism (2020) 110:154317. doi: 10.1016/j.metabol.2020.154317

97. Iacobellis G, Secchi F, Capitanio G, Basilico S, Schiaffino S, Boveri S, et al. Epicardial Fat Inflammation in Severe COVID-19. Obes (Silver Spring) (2020) 28:2260-2. doi: 10.1002/oby.23019

98. Grodecki K, Lin A, Razipour A, Cadet S, McElhinney PA, Chan C, et al. Epicardial Adipose Tissue Is Associated With Extent of Pneumonia and Adverse Outcomes in Patients With COVID-19. Metabolism (2021) 115:154436. doi: 10.1016/j.metabol.2020.154436

99. Commandeur F, Goeller M, Razipour A, Cadet S, Hell MM, Kwiecinski J, et al. Fully Automated CT Quantification of Epicardial Adipose Tissue by Deep Learning: A Multicenter Study. Radiol Artif Intell (2019) 1:e190045. doi: 10.1148/ryai.2019190045

100. Hickson DA, Liu J, Bidulescu A, Burchfiel CM, Taylor HA, Petrini MF. Pericardial Fat Is Associated With Impaired Lung Function and a Restrictive Lung Pattern in Adults: The Jackson Heart Study. Chest (2011) 140:1567-73. doi: $10.1378 /$ chest.11-0258

101. Deng M, Qi Y, Deng L, Wang H, Xu Y, Li Z, et al. Obesity as a Potential Predictor of Disease Severity in Young COVID-19 Patients: A Retrospective Study. Obesity (2020) 28:1815-25. doi: 10.1002/oby.22943

102. Iacobellis G, Malavazos AE, Basilico S, Tresoldi S, Rinaldo RF, Dubini C, et al. Epicardial Fat Inflammation Response to COVID-19 Therapies. Obes (Silver Spring) (2021). doi: 10.1002/oby.23232

103. Couselo-Seijas M, Almengló CM, Agra-Bermejo R, Luis Fernandez Á, Alvarez E, González-Juanatey JR, et al. Higher ACE2 Expression Levels in Epicardial Cells Than Subcutaneous Stromal Cells From Patients With Cardiovascular Disease: Diabetes and Obesity as Possible Enhancer. Eur J Clin Invest (2020) 51(5):e13463. doi: 10.1111/eci.13463

104. Patel VB, Mori J, McLean BA, Basu R, Das SK, Ramprasath T, et al. ACE2 Deficiency Worsens Epicardial Adipose Tissue Inflammation and Cardiac Dysfunction in Response to Diet-Induced Obesity. Diabetes (2016) 65:85-95. doi: $10.2337 / \mathrm{db} 15-0399$
105. Flinn B, Royce N, Gress T, Chowdhury N, Santanam N. Dual Role for Angiotensin-Converting Enzyme 2 in Severe Acute Respiratory Syndrome Coronavirus 2 Infection and Cardiac Fat. Obes Rev (2021) 22:e13225. doi: 10.1111/obr.13225

106. Abrishami A, Eslami V, Baharvand Z, Khalili N, Saghamanesh S, Zarei E, et al. Epicardial Adipose Tissue, Inflammatory Biomarkers and COVID-19: Is There a Possible Relationship? Int Immunopharmacol (2021) 90:107174. doi: 10.1016/j.intimp.2020.107174

107. Zhao L. Obesity Accompanying COVID-19: The Role of Epicardial Fat. Obesity (2020) 28:1367-7. doi: 10.1002/oby.22867

108. Malavazos AE, Goldberger JJ, Iacobellis G. Does Epicardial Fat Contribute to COVID-19 Myocardial Inflammation? Eur Heart J (2020) 41:2333. doi: 10.1093/eurheartj/ehaa471

109. Kim I-C, Han S. Epicardial Adipose Tissue: Fuel for COVID-19-Induced Cardiac Injury? Eur Heart J (2020) 41(24):2334-5. doi: 10.1093/eurheartj/ ehaa 474

110. Iacobellis G, Malavazos AE, Ferreira T. COVID-19 Rise in Younger Adults With Obesity: Visceral Adiposity Can Predict the Risk. Obes (Silver Spring) (2020) 28:1795. doi: 10.1002/oby.22951

Conflict of Interest: The authors declare that the research was conducted in the absence of any commercial or financial relationships that could be construed as a potential conflict of interest.

Publisher's Note: All claims expressed in this article are solely those of the authors and do not necessarily represent those of their affiliated organizations, or those of the publisher, the editors and the reviewers. Any product that may be evaluated in this article, or claim that may be made by its manufacturer, is not guaranteed or endorsed by the publisher.

Copyright (c) 2021 Lasbleiz, Gaborit, Soghomonian, Bartoli, Ancel, Jacquier and Dutour. This is an open-access article distributed under the terms of the Creative Commons Attribution License (CC BY). The use, distribution or reproduction in other forums is permitted, provided the original author(s) and the copyright owner(s) are credited and that the original publication in this journal is cited, in accordance with accepted academic practice. No use, distribution or reproduction is permitted which does not comply with these terms. 